\title{
Modeling and Simulation of Space Vector Modulated Matrix Converter fed Induction Motor
}

\author{
R.Anu ${ }^{1}$, L.Sarojini ${ }^{2}$, E.P.Sangeetha ${ }^{3}$ \\ Department of EEE, K.Ramakrishnan College of Engineering, Tamilnadu, India ${ }^{1,3}$ \\ Department of EEE, Periyar Maniammai Institute of science and Technology, Tamilnadu, India ${ }^{2}$
}

\begin{abstract}
Matrix Converters (MC) are reduced voltage source converters equipped for giving variable voltage variable recurrence at the yield. Contrasted and customary topologies the MC does not require a middle of the road dc interface and furnishes sinusoidal yield waveform with least higher request music. To yield higher RMS O/P voltage, it is proposed to utilize Space Vector Modulation (SVM) calculation for the voltage control of converter. This calculation utilizes a less complex technique than the other control calculations to control the info power factor. Also, it has lower exchanging misfortunes and simple execution. Reproduction has been executed for different yield frequencies at solidarity info power factor. The recreation aftereffects of yield voltage waveforms are given their spectra.
\end{abstract}

Keywords: Matrix Converters (MC), Space Vector Modulation (SVM), RMS O/P voltage, Rotor Speed (RPM)

\section{INTRODUCTION}

The Matrix converter is the most general converter-type in the family of $\mathrm{AC}$ to $\mathrm{AC}$ direct converters. While the matrix converter fulfills the requirements to provide a sinusoidal voltage at the load side, it is also possible to adjust the unity power factor on the mains side under certain conditions. Since there is no d.c.-link as in common converters, the matrix converter can be built as a full-silicon structure (H.Altun and S.Sünter,2001). However, a mains filter is necessary to smooth the pulsed currents on the input side of the matrix converter. Using a sufficiently high pulse frequency, the output voltage and input current both are shaped sinusoidal.

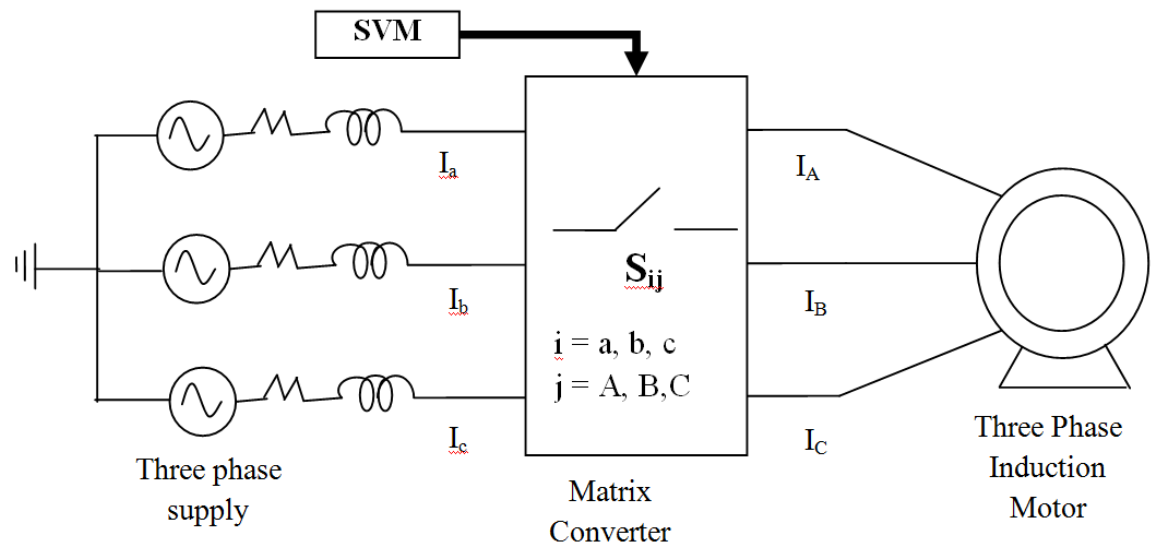

Figure 1 Matrix converter of three phase induction motor

\section{Space Vector Representation Of Three-Phase Variables}

For a balanced three-phase sinusoidal system the instantaneous voltages are expressed as

$$
\left[\begin{array}{c}
V_{A B}(t) \\
V_{B C}(t) \\
V_{C A}(t)
\end{array}\right]=V_{01}\left[\begin{array}{c}
\cos \omega_{0} t \\
\cos \left(\omega_{0} t-120\right) \\
\cos \left(\omega_{0} t-240\right)
\end{array}\right]
$$




\section{International Journal of Innovative Research in Electrical, Electronics, Instrumentation and Control Engineering}

Vol. 7, Issue 6, June 2019

This can be analyzed in terms of complex space vector

$$
\mathrm{V}_{0}=\frac{2}{3}\left[\mathrm{~V}_{\mathrm{AB}}(\mathrm{t})+\mathrm{V}_{\mathrm{BC}}(\mathrm{t}) \mathrm{e}^{\mathrm{j} 2 \pi / 3}+\mathrm{V}_{\mathrm{BC}}(\mathrm{t}) \mathrm{e}^{\mathrm{j} 4 \pi / 3}\right]=\mathrm{V}_{0 \mathrm{l}} \mathrm{e}^{\mathrm{j} \omega_{0} \mathrm{t}}
$$

Where, $\mathrm{e}^{\mathrm{j} \theta}=\cos \theta+\mathrm{j} \sin \theta$ represents a phase shift operator and $2 / 3$ is a scaling factor equal to the ratio between the magnitude of the output line-to-line voltage and that of the output voltage vector. $\omega_{0}$ is the angular velocity of the vector and its magnitude is $\mathrm{V}_{0 \mathrm{l}}$.

Similarly, the space vector representation of the three-phase input voltage is given by

where ,

$$
\vec{V}_{i}=V_{i} e^{j\left(\omega_{i} t\right)}
$$

$V_{i}$ is the amplitude and $\omega_{i}$ is the constant input angular velocity.

If a balanced three-phase load is connected to the output terminals of the converter, the space vector form of the threephase output current and input current is given by

$$
\begin{aligned}
& \overrightarrow{\mathrm{I}}_{0}=\mathrm{I}_{0} \mathrm{e}^{\mathrm{j}\left(\omega_{0} \mathrm{t}-\emptyset_{0}\right)} \\
& \overrightarrow{\mathrm{I}}_{\mathrm{i}}=\mathrm{I}_{\mathrm{i}} \mathrm{e}^{\mathrm{j}\left(\omega_{\mathrm{i}} \mathrm{t}-\emptyset_{\mathrm{i}}\right)}
\end{aligned}
$$

Respectively, where $\emptyset_{0}$ is the lagging phase angle of the output current to the output voltage and $\emptyset_{\mathrm{i}}$ represents the input current to the input voltage.

Group 1 (Synchronously rotating vectors): This First group consists of six combinations in which each of the three output phases are connected to a different input phases. Each of them generates a three-phase output voltage having magnitude and frequency equivalent to those of the input voltages but with the phases sequence altered from that of the input voltages. As the input frequency is not related to the output frequency, the SVM could not use the above said vectors to synthesize the reference voltage vector that rotates at the frequency $\omega_{0}$.

Group 2 (Stationary vectors): This second group is classified into three sets. Which has six combinations each and has a common feature of connecting two output phases to the same input phase. The corresponding vectors of these combinations have a constant phase angle. The magnitude of these vectors, however vary with changes of the instantaneous input line-line voltages.

Group 3 (Zero vectors.): The last three combinations in the table form the last group. These have three output phases switched simultaneously on to the same input phase resulting in zero line-line voltages and are called zero voltage vectors. Output line voltage and input current space vectors are used in the application of the space vector control technique to the matrix converter.

Selection of Stationary Vectors: Switch combinations for matrix converter control, the SVM method is designed to choose appropriately four out of 18 switch combinations from a second group at any instant.

\section{SIMULATION MODEL}

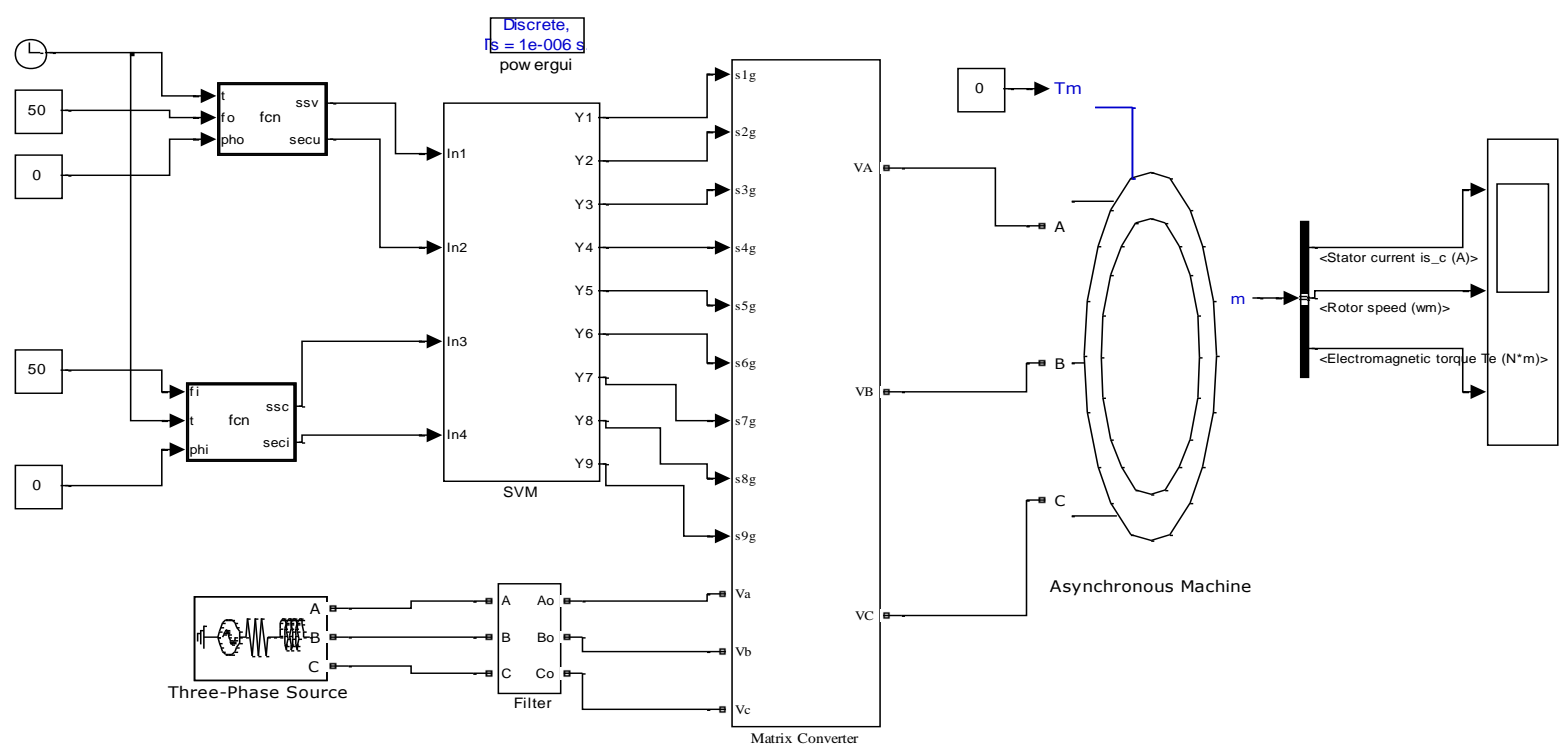

Figure 5. Simulink Model of the Controlled system 
International Journal of Innovative Research in Electrical, Electronics, Instrumentation and Control Engineering

Vol. 7, Issue 6, June 2019

\section{Simulation Result}
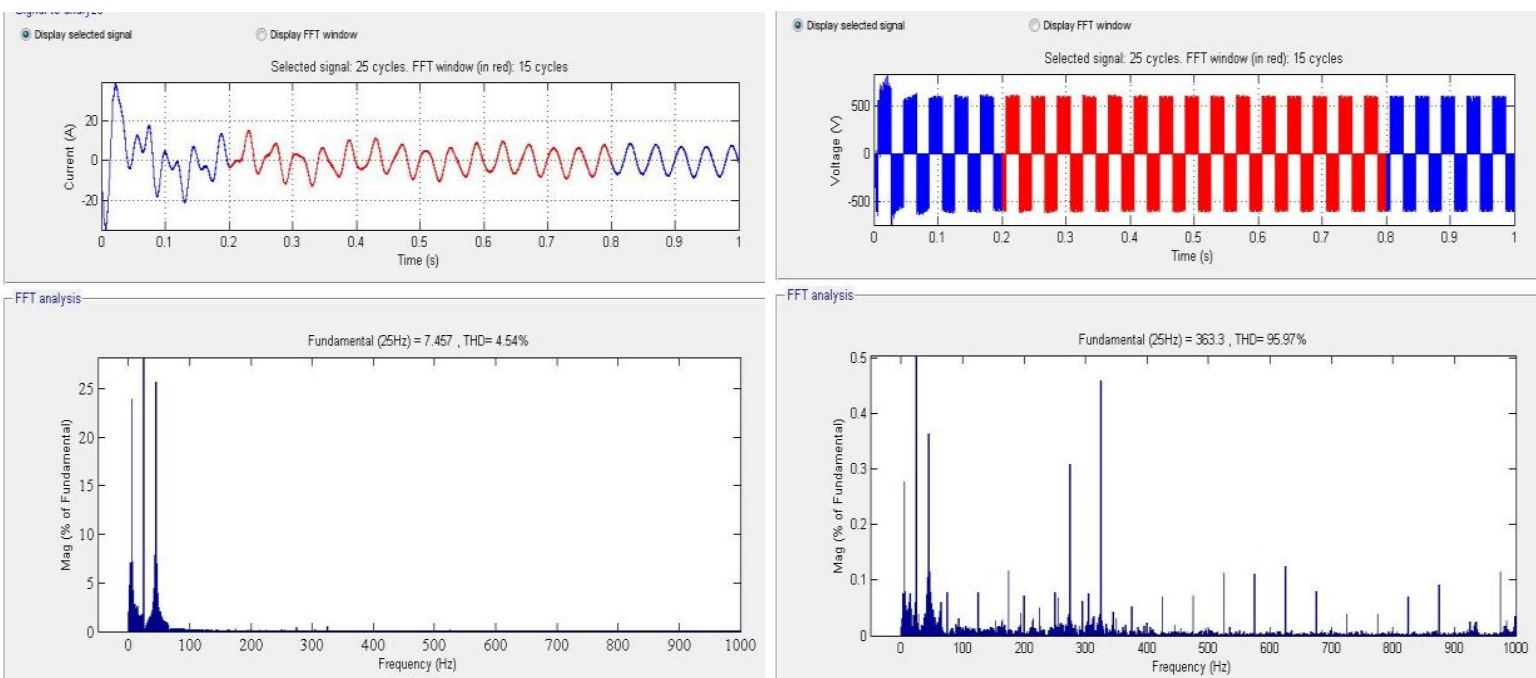

Figure 7 (a)

Figure 7 (b)

Figure 7. Matrix Converter output frequency - $100 \mathrm{HZ}$ (a) Output voltage and THD (b) Output current and THD
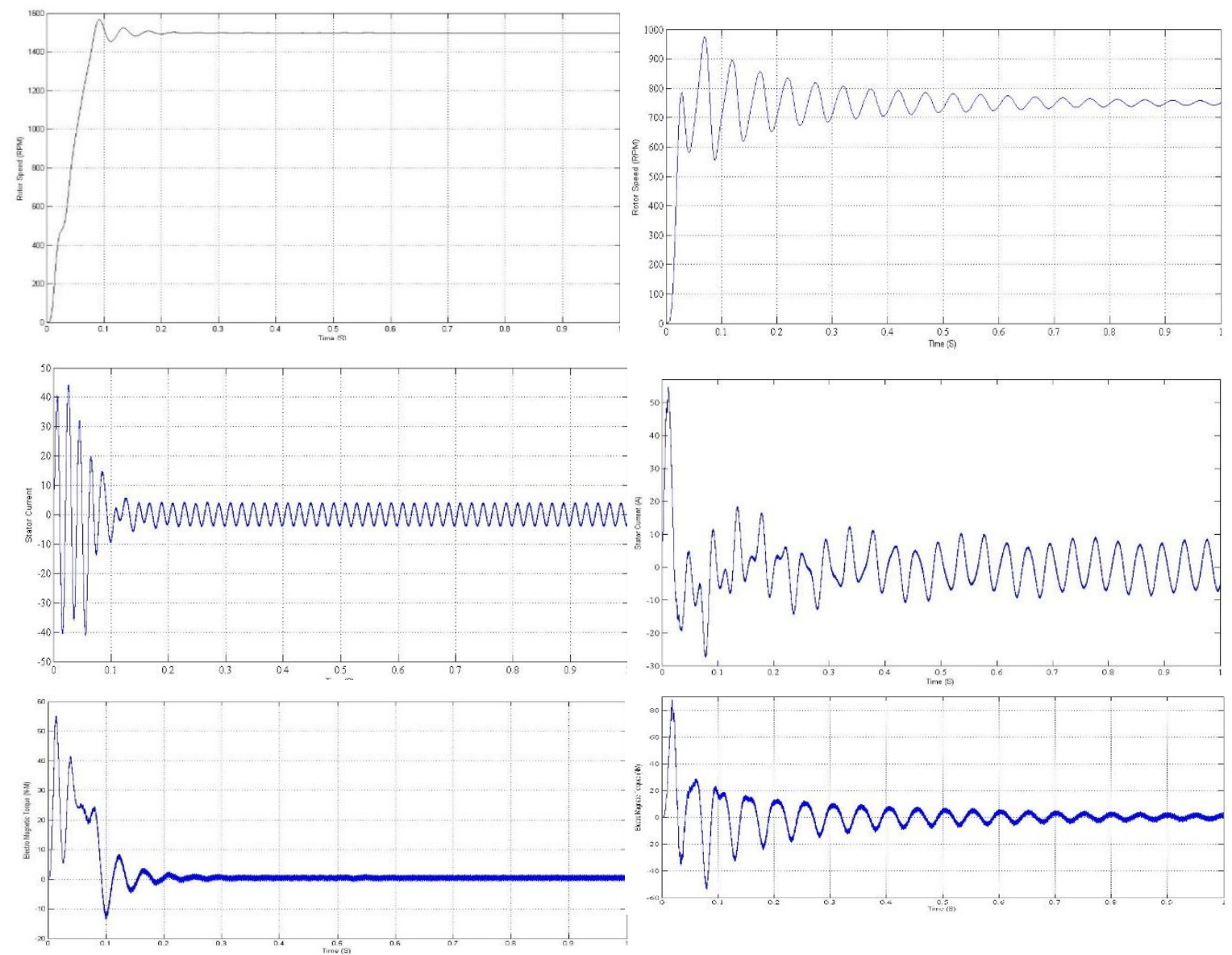

Figure 8(a)

Figure 8 (b)

Figure 8. Stator Current, Rotor Speed, Electromagnetic Torque for Matrix Converter Fed Induction Motor drive (a) $50 \mathrm{HZ}$ frequency (b) $25 \mathrm{HZ}$ frequency 


\section{International Journal of Innovative Research in Electrical, Electronics, Instrumentation and Control Engineering}

Vol. 7, Issue 6, June 2019

III. RESULT \& DISCUSSION

Table 2. Comparison statement for rotor speed and THD

\begin{tabular}{|c|c|c|c|}
\hline $\begin{array}{c}\text { Frequency } \\
(H Z)\end{array}$ & $\begin{array}{c}\text { Rotor Speed } \\
(\text { RPM })\end{array}$ & \multicolumn{2}{|c|}{ Matrix Converter output THD (\%) } \\
\cline { 3 - 4 } & 1500 & Current & Voltage \\
\hline 50 & 750 & 3.11 & 95.79 \\
\hline 25 & 4.54 & 95.97 \\
\hline
\end{tabular}

The table 2 represents the comparison between two frequencies. The rotor speed were maximum in the both conditions and the THD value is also obtained for the matrix converter output voltage and current. The matrix converter response rapidly reached the maximum speed and maintained at the constant speed.

\section{CONCLUSION}

In this investigation, displaying and recreation of the three stage Matrix Converter with Induction Motor utilizing space vector control calculation have been acknowledged in Simulink/Matlab bundle program. The information and yield waveforms of the converter for different yield frequencies have been explored. In the Simulation results exhibited over the yield waveforms did not have real music aside from those around exchanging recurrence. From the symphonious investigation, plainly the main consonant of the unfiltered input current is in stage with the information voltage.

\section{REFERENCES}

[1]. H.Altun and S.Sünter, "Simulation and Modelling of Vector Controlled 3-Phase Matrix Converter Induction Motor Drive" ELECO'01, Bursa, Nov. 7-11, 2001, pp .98-102.

[2]. Navaneethan. R, Ilango.R,Prabhakaran.V (2015),'design and control for bidirectional AC -DC converters for plug-in Hybrid Electric vehicle', International Journal of Engineering and Applied Sciences.ISSN no. 2394-3661,vol. 2, no.5, pp.5-9.

[3]. E Erdem, Y. Tatar, S. Sunter, "Modeling and Simulation of Matrix Converter Using Space Vector Control Algorithm". EUROCON2005- IEEE International Conference on Computer as a tool, November 21-24, Belgrade, Serbia \& Montenegro, pp. 1228- 1231, 2005.

[4]. Zuckherberger A, Weinstock D, lexandrovitz A (1996) Simulation of three-phase loaded matrix converter. IEE Proc Trans Electr Power Applic 143:294-300.

[5]. Su“ nter S, Altun H, Clare JC (2002) A control technique for compensating the effects of input voltage variations on matrix converter modulation algorithms. Electric Power Components Syst 30:807-822.

[6]. Venkatesa Vimal Chand M.R.V,Ilango.R(2014)'DTC VSI fed Induction Motor Drive by using Near state PWM method with reduced common mode voltage', International journal of Innovative research in Engineering Science \& Technology, ISSN.no.2320-981X, vol.2 no.01, pp.73-78.

[7]. T. F. Podlesak, D. C. Katsis, P. W. Wheeler, J. C. Clare, L. Empringham, and M. Bland, "A 150 kVA vector - controlled matrix converter induction motor drive", IEEE Transactions on Industry Applications, vol. 41, no:3, pp. 841-847, 2005.

[8]. Odaka A, S.I., Ohgushi H, Tamai Y, Mine H, Ito J. A Pam Control Method For Matrix Converter. In Proc 2005 Japan Industry Applications Society Conference. 2005.

[9]. M.Jayalakshmi, G Asha and K Keerthana, control of single phase Z- Source Inverter fed Induction motor using simple boost controller, International Journal of Emeeging trends in Electrical and Electronics,vol.10,issue 10,pp.44-48,2014.

[10]. A Subramania Siva, M Bhavani, Mitigation of Harmonics by shunt Active power filter Synchronous Dtection method, International Journal of Engineering Trends and Technology,pp.2231-5381.

[11]. Karthik. S,Jegan.C,Ilango.R(2014)' SVPWM controlled Permanent Magnetb Synchoronous Motor',International Journal of Engineering and Management Research, ISSN No. 2250-0758, vol. 4, no.02.pp. 22-28.

[12]. R PreethiRajaiah, R John Britto, Optic disc boundary detection and cup segmentation for prediction of glaucoma, International Journal of Science, Engineering and Technology Research (IJSETR), vol.3, issue 10, pp. 2665-2672,2014.

[13]. Vinoth Kumar. C \& Santhosh Kumar. B Ganesh.N, Udaya Kumar. M, Optimization of Cutting Parameters in Turning of En 8 Steel using Response Surface Method \& Genetic Algorithm, International Journal of mechanical Engineering and Robotics Research, vol.3,issue 2278 0149, pp.75-86, 2014.

[14]. B.KiranBala , J.Lourdu Joanna, Multi Modal Biometrics using Cryptographic Algorithm, European Jour of Academic Essays 1(1): 6-10, 2014.

[15]. S Shabina, Smart Helmet Using RF and WSN Technology for Underground Mines Safety, Proceedings of International Conference on Intelligent Computing Applications, pp.305-309,2014.

[16]. Revathi, A Jeyalakshmi, C "Robust Speech Recognition in Noisy Environment using Perceptual Features and Adaptive Filters", Proceedings of 'International Conference on Communication and Electronics Systems (ICCES 2017), pp.692-696, 2018.

[17]. M. Venkatachalapathy and A. Edward Samuel, An Alternative Method for Solving Fuzzy Transportation Problem using Ranking Function, International Journal of Applied Mathematical Sciences, Volume 9, Number 1 (2016), pp. 61-68. 